\title{
Fabrication of Solar Powered Multi Operated Agriculture Machine
}

\author{
B S Kanthraju, Akshay Kumar G, Kiran Kumar C, Chandan B, Kiran Kumar P M
}

\begin{abstract}
Today's technology is marching closer to the speedy boom of all sectors such as the rural sector. To meet the future food demands, the farmers should put into effect the brand new strategies so as to now no longer have an effect on the soil texture however will growth the general crop production. The intention of this work is to fabricate and design a solarpowered multi operated machine.The seed sowing machine is a key element of the rural field. The numerous technology utilized in India for seed sowing and fertilizer placement are guide, ox, and tractor operators. The guide and ox operator strategies are time-ingesting and productiveness is low. The tractor is strolling on fossil gasoline which emits carbon dioxide and different pollutants each second. This proof has caused sizable air, water, and noise pollutants and most significantly has caused a actual electricity disaster withinside the close to destiny, with a view to make the improvement of our farmer in addition to country sustainable and motive much less damage to our environment. Now the method of this mission is to broaden the multi operated machine that's to reduce the running price and the time for digging in addition to function on easy strength
\end{abstract}

Keywords : Mechanization, digging, sowing

\section{INTRODUCTION}

\section{A. History of Agriculture Mechanization in India}

The tale of the improvement of agricultural mechanization in India is each captivating and in lots of ways, pretty remarkable. The country has moved ahead over the last six a long time from one wherein it then confronted extreme food shortages to in which nowadays it has end up an exporter of many food commodities and a main exporter of different business products, inclusive of agricultural tractors. This has been accomplished not with standing a greater than three-fold boom in its populace and a mere boom to the arable land area. Today, India ranks $2 \mathrm{~d}$ amongst different nations the world over in farm output. Agriculture and allied sectors like fisheries and forestry accounted for $13.7 \%$ of the GDP in 2013 , approximately $50 \%$ of the workforce. The monetary contribution of agriculture to India's GDP is reducing regularly with the countries broad-primarily based totally monetary increase. According to WHO (world health organization), Slow agricultural increase is a hobby for

Manuscript received on January 27, 2021.

Revised Manuscript received on February 22, 2021.

Manuscript published on February 28, 2021

* Correspondence Author

B S Kanthraju*, Department of Mechanical Engineering, Don Bosco Institute of Technology, Bangalore, India. Email: kanthraj.harish@gmail.com

Akshay Kumar G, Department of Mechanical Engineering, Don Bosco Institute of Technology, Bangalore

Kiran Kumar C, Department of Mechanical Engineering, Don Bosco Institute of Technology, Bangalore, India

Chandan B, Department of Mechanical Engineering, Don Bosco Institute of Technology, Bangalore, India

Kiran Kumar P M, Department of Mechanical Engineering, Don Bosco Institute of Technology, Bangalore, India policymakers as $2 / 3$ of India's human beings depend upon rural employment for living. An ICAR study (2004-2007) confirmed that 34.2 percentage of injuries in agriculture had been because of hand gear, with sickles and spades worried in forty six percentage of farm accidents. Implications of accidents because of hand gear are extreme as those accidents are very painful and disabling because of behind schedule treatment. A survey performed in India confirmed that 70 percentage of agricultural hand gear accidents had a recuperation time of greater than seven days. Thus, growing farm equipment greater ideal to the neighbourhood situations is critical in order that accidents and issues that include using hand gear may be abated even as making agricultural practices greater productive.

B. Advantages of Mechanization in Farming

Farm mechanization Hs been acknowledged to offer some of monetary and social advantages to farmers. Primarily some of the monetary advantages is the stepped forward yield that comes because of more stage of mechanization. Looming water shortage disaster together with the want to make certain meals safety withinside the country, the advantages of farm mechanization makes it a important issue of shaping the destiny of Indian agriculture.

1) Input financial savings : studies have proven a right away courting among farm mechanization and farm yield. Farm mechanization is stated to offer some of inter financial savings.

2) Increase in performance : aside from the above-said inputs, farm equipment additionally allows in growing the performance of farm hard work and lowering drudgery and workloads. It is expected that farm mechanization can assist lessen time through about $15-20$ percentage. Additionally, it allows in enhancing the harvest and lowering the post-harvest losses, and enhancing the high-satisfactory of cultivation. These advantages and the financial savings in input assist withinside the discount of manufacturing prices and permit farmers to earn greater income.

3) Social Advantages : there are diverse social advantages of farm mechanization as well.

4) Helps withinside the conversion of uncultivable Land to agricultural land via superior tilling strategies and additionally in transferring land.

5) Used for feed and fodder cultivation through draught animals closer to melas manufacturing.

6) Decrease in workload on girls as a right away effect of the stepped forward performance of hard work. Improvement withinside the protection of farm practices.

7) Helps in encouraging the teenagers to enrol in farming and entice greater human beings to work and stay in rural areas.

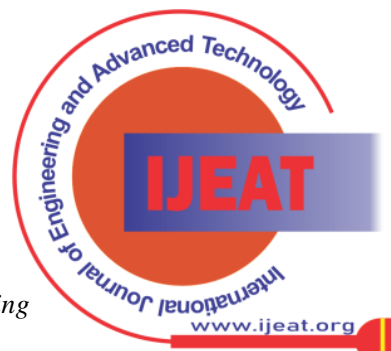




\section{LITERATURE REVIEW}

Since last century, mechanization is continuously adapted in agriculture. Various developments in farm machineries have been observed. The machineries with high costs and with low costs are available. The approach toward various multipurpose, handy equipment is also seen. Affordable and easy to use machines have been developed.

1. M.V.Achutha :A agricultural researcher studied the factors that influence the performance of a agro machine which performs operations such as sowing, fertilizing, spraying and intercultivation. Based on this study a plug matrix selection criteria was used to select best among the concepts developed by them, the primary reason to reject other concepts was that it had mechanisms like chain-sprocket, gears etc. which would increase the complexity in manufacturing.

2. Kalingwar C.M., Kadam.N.S., HumbadeA.B. :They made analysis on multipurpose agriculture machine, This Project gives work on design of a brand new agricultural multipurpose machine for use for diverse applications. As international opposition is urgent farmers on many fronts, mechanized agriculture has emerge as one of the critical current agricultural methods. in India $60 \%$ populace concerned in agriculture, Conventional mechanized structures may

also growth productiveness however are much less adaptive and flexible. As a consequence, there had been projects in growing superior mechanized structures.

3. Mr. Sharanabasappa Bolashetty :The most effective manner is to automate it however we can not completely automate it is because of few constraints such because it would require power that allows you to now no longer be in most cases to be had in villages, they may be requiring Microprocessor and sensor that allows you to once more boom the price and can require talent to apply it. This would possibly assist us attaining their purpose with the aid of using lowering the person energy in addition to price. In this design, fabricate and checking out of semi-automatic multipurpose agricultural wheel hoe to apply of numerous agricultural operations.

\section{METHODOLOGY}

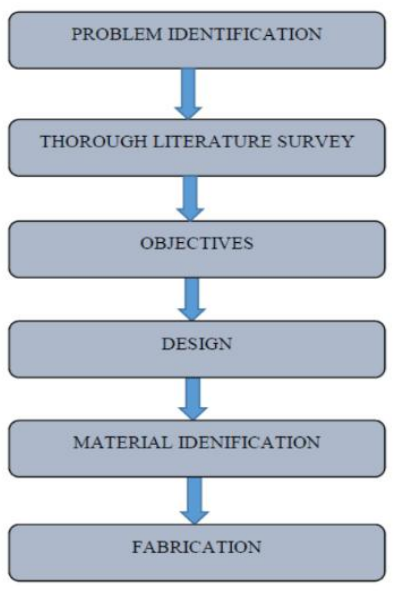

Fig. 1. Flow Chart

As we all know most of the Indian farmers are poor and they are not economical to purchase a full featured existing cultivating machine. There we identified the problem and discussed to find a solution. Later we made some thorough literature survey that if any projects were made same as what we are doing. It's far located that lot of labour has been executed on this area thought, those thoughts aren't been carried out well in real agriculture field. This Is because of excessive cost extra preservation and skilful for rural people. Any work at its beginning accommodates of placing the goal. Then comes thoughts and their evaluation to get to the first-class technique to gain the goal. The major goal of this project is to manufacture a solar powered multi operated agriculture machine. This task is to assist small scale farmers to domesticate the farm with much less attempt and minimum cost. . Coming to design, we are going to design in such a way that it should be portable. After design we are going to do some market surveys and identify the required material and accessories for the project and we are going to purchase it at the best price. The body is made from slight metal which has a excessive resistance to breakage and may resist excessive tensile and effect strength. . After identifying the all materials the various types of fabrication process is carried out to complete the project.

\section{WORKING PRINCIPLE}

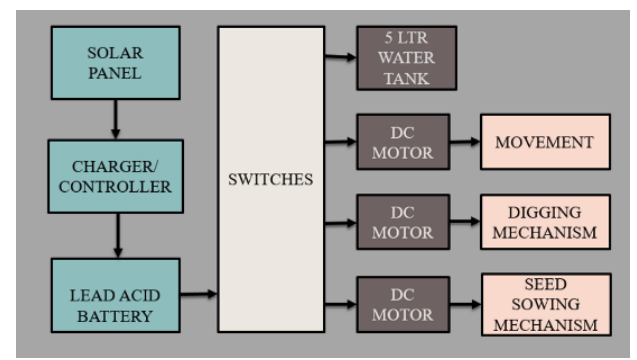

Fig. 2. Block Diagram

In this project we will be using the solar energy for the utilization of the machine. The sun's energy is transformed into electric strength that is saved in battery and the battery is used for the sowing, digging and different agricultural process. The panel is constant to the body and the panel is hooked up to the battery and it is hooked up to the switches and the separate DC motors have separate switches to manipulate and additionally the spraying of water is likewise controlled. The distinct Dc motors are used to manipulate the motion and different processes

\section{STUDY OF PHOTOVOLTAIC CELL}

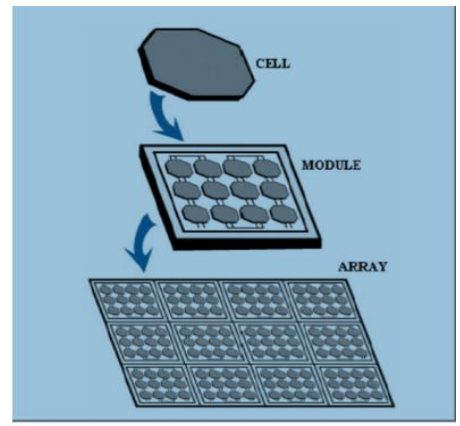

Fig. 3. Photovoltaic Cell

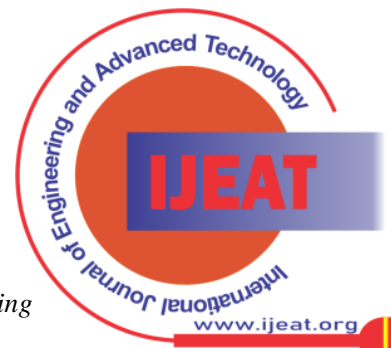


The photoelectric impact turned into first referred to through a French physicist, in 1839, who located that positive substances could produce small quantities of electrical modern while uncovered to mild.

In 1905, Albert Einstein defined the character of mild and the photoelectric impact on which photovoltaic generation is based, for which he later receive a Nobel prize in physics.

The first photovoltaic module constructed through bell Laboratories' in 1954. It turned into billed as a solar battery and turned into more often than not only a interest because it turned into too high-priced to benefit great use. In the 1960s, the space enterprise commenced to make the primary extreme use of the generation to offer strength aboard spacecraft. Through the space programs, the generation advanced, its reliability turned into established, and the fee commenced to decline. During the energy disaster with inside the 1970s, photovoltaic generation won reputation as a supply of strength for non-area applications. The solar cells which you see on calculators and satellites also are referred to as photovoltaic cells, which because the cell implies convert daylight at once into electricity. A module is a set of cells related electrically and packaged right into a frame.

\section{DECLINATION}

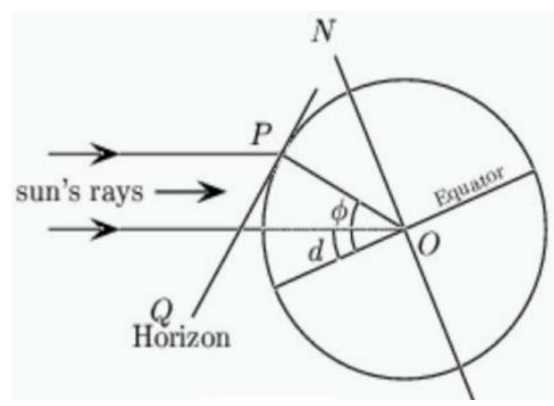

Fig. 4.Declination of Sun Rays

Declination can be described because the attitude among the road becoming a member of theFacilities of the solar and earth and its projection at the equatorial plane. Declination varies from a maximum value of $23.45^{\circ} 0$ J June twenty first to the minimum value of $-23.45^{\circ}$ on December twenty first. Mathematically it could be calculated through the subsequent relation.

$$
\begin{gathered}
\mathrm{d}=23.45^{*} \sin [(360 / 365) *(284+\mathrm{n})] \\
\text { where } \mathrm{n}=\text { day of the year }
\end{gathered}
$$

\section{DESIGN}

\section{Major design factors}

In growing a layout, designers ought to don't forget the way where in choices have an effect on manufacturing operations production costs, product performance, look, and patron acceptance. Many elements which might be apparently a ways eliminated from engineering issues can turn out to be essential layout elements. Some of these, along side different applicable rules, are highlighted below.

1. The layout to fulfil power and stiffness requirements, however overdesigning now no longer handiest constitutes a terrible engineering exercise however additionally wastes substances and labour and will increase manufacturing and delivery costs.

2. Safety elements ought to be realistic.
3. As an appealing look can be vital in regions uncovered to view, the drawing or specs ought to imply the ones welds that should be floor or in any other case conditioned to decorate and look.

4. Deep, symmetrical sections ought to be used to decrease distortion.
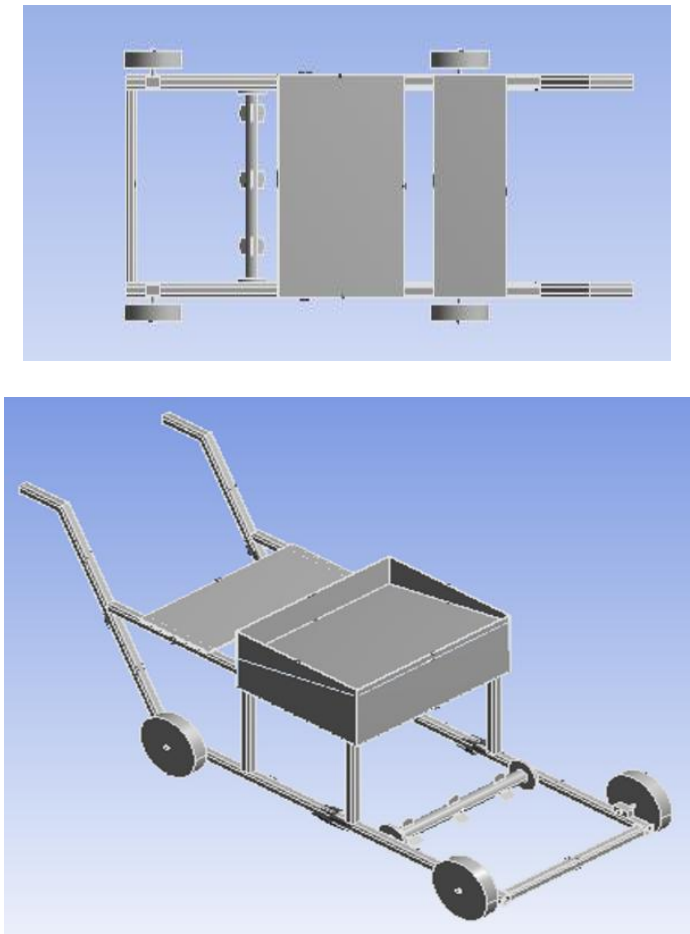

Fig. 5. Machine Design

Facility Required For Proposed Work :

Software Required:

1. CATIA : To create 3D model of parts of the multiple crop cutter

2. ANSYS : To analyse the model under the different loading condition to check the stress concentration and deformation.

\section{CONSTRUCTION}

1. The body of the machine is a product of Mild Steel. The wheels are linked to the body, which moved with the help usage of a DC motor.

2. The front of the body harvester rotor is hooked up and this rotor is turned around through the usage of a DC motor.

3. In the centre of the body, 3 diggers are linked to dig the soil. The nut and bolt assembly is used withinside the body, through the usage of nut and bolt up and down function of digger is done.

4. The funnel is used to save the seeds. With the help of hoses, the motion of seeds to soil is done with the assist of a low pace motor.

5. At the end of the body, the leveller is hooked up and the sprayer is fixed to fertilize at the crop.

6. The pinnacle of the body the solar panel is fixed. The panel is hooked up to the battery.

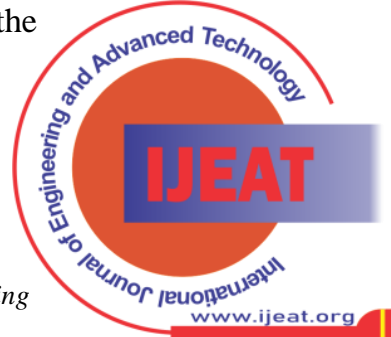




\section{Fabrication of Solar Powered Multi Operated Agriculture Machine}

\section{FINAL MODEL}
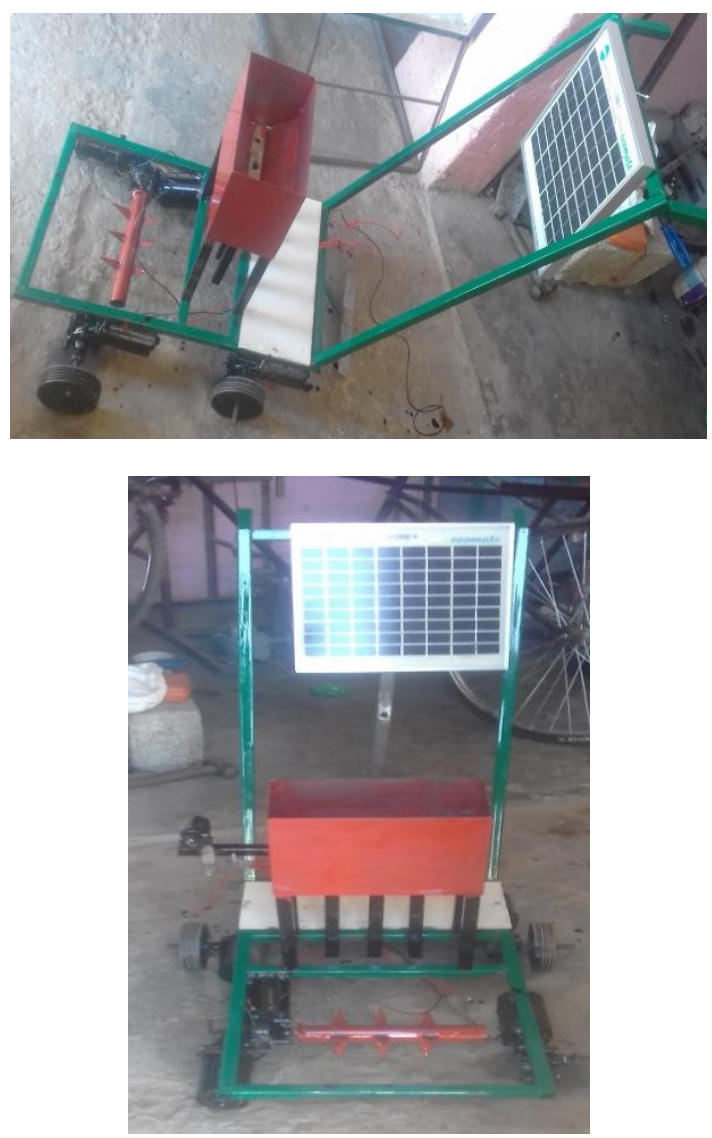

Fig. 6. Final Model

\section{CONCLUSION}

In reality our multipurpose agricultural system may be used for digging, sowing, spraying, and additionally levelling. Our crew has effectively blended many thoughts from numerous fields of mechanical engineering and agricultural expertise to enhance the yield and through decreasing the exertions attempt and expenses. The complete concept of multipurpose system is a brand new concept and may be effectively carried out in actual existence situations.

\section{REFERENCES}

1. Akhilesh K.Bhatkar1, P. B. Khope, P. S. Chaudhari, A REVIEW: Introduction To Agriculture ,Ijret: International Journal of Research in Engineering and Technology E-ISSN: 2319-1163 |P-ISSN: 2321-7308

2. R. Joshua, V. Vasu and P. Vincent, Solar Sprayer - An Agriculture Implement International Journal of Sustainable Agriculture 2 (1): 16-19, 2010 ISSN 2079-2107@ IDOSI Publications, 2010.

3. Achutha, M.V. Sharath Chandra. N, Nataraj.G.K "Concept Design And Analysis Of Multipurpose Farm Equipment" "International Journal Of Innovative Research In Advanced Engineering" (IJIRAE) ISSN: 2349-2763 Issue 02, Volume 3 (February 2016).

4. Amir Hussain "frontline demonstration on bullock drawn planter enhances yield of soya bean crop. International journal of farm science 1(2):123128, 2011.

5. Amol B. Rohokale, Pavan D. Shewale, SumitB.Pokharkar and Keshav K. Sanap "Introduction To Agriculture" pp. 180-186, IAEME.

6. A. Wankhede,A. P. Rathod, A. V. Gorde, R. K. "Design Modification Of Advance Seed Sowing Cum Fertilizer Machine" "international journal for engineering applications and technology".

\section{AUTHORS PROFILE}

B S Kanthraju, Department of Mechanical Engineering, Don Bosco Institute of Technology, Bangalore, India. Email: kanthraj.harish@gmail.com 